\title{
Medical Specialists' Perspectives on the Influence of Electronic Medical Record Use on the Quality of Hospital Care: Semistructured Interview Study
}

Rube van Poelgeest ${ }^{1}$, MSc; Augustinus Schrijvers ${ }^{1}$, Prof Dr; Albert Boonstra ${ }^{2}$, Prof Dr; Kit Roes ${ }^{3}$, Prof Dr

\footnotetext{
${ }^{1}$ Julius Center, University Medical Center, University of Utrecht, Utrecht, Netherlands

${ }^{2}$ Faculty of Economics and Business, University of Groningen, Groningen, Netherlands

${ }^{3}$ Radboudumc, University of Nijmegen, Nijmegen, Netherlands
}

\section{Corresponding Author:}

Rube van Poelgeest, MSc

Julius Center

University Medical Center

University of Utrecht

Universiteitsweg 100

Utrecht, 3584 CG

Netherlands

Phone: 31620139545

Email: rube.van.poelgeest@ planet.nl

\section{Abstract}

Background: Numerous publications show that electronic medical records (EMRs) may make an important contribution to increasing the quality of care. There are indications that particularly the medical specialist plays an important role in the use of EMRs in hospitals.

Objective: The aim of this study was to examine how, and by which aspects, the relationship between EMR use and the quality of care in hospitals is influenced according to medical specialists.

Methods: To answer this question, a qualitative study was conducted in the period of August-October 2018. Semistructured interviews of around 90 min were conducted with 11 medical specialists from 11 different Dutch hospitals. For analysis of the answers, we used a previously published taxonomy of factors that can influence the use of EMRs.

Results: The professional experience of the participating medical specialists varied between 5 and 27 years. Using the previously published taxonomy, these medical specialists considered technical barriers the most significant for EMR use. The suboptimal change processes surrounding implementation were also perceived as a major barrier. A final major problem is related to the categories "social" (their relationships with the patients and fellow care providers), "psychological" (based on their personal issues, knowledge, and perceptions), and "time" (the time required to select, implement, and learn how to use EMR systems and subsequently enter data into the system). However, the medical specialists also identified potential technical facilitators, particularly in the assured availability of information to all health care professionals involved in the care of a patient. They see promise in using EMRs for medical decision support to improve the quality of care but consider these possibilities currently lacking.

Conclusions: The 11 medical specialists shared positive experiences with EMR use when comparing it to formerly used paper records. The fact that involved health care professionals can access patient data at any time they need is considered important. However, in practice, potential quality improvement lags as long as decision support cannot be applied because of the lack of a fully coded patient record.

(JMIR Hum Factors 2021;8(4):e27671) doi: 10.2196/27671

\section{KEYWORDS}

electronic medical record (emr); hospitals; quality; health care; medical specialist 


\section{Introduction}

In modern-day hospitals, IT is present in many forms. Among these are information systems, networks, databases, and websites. An electronic medical record (EMR) comprehensively includes all information to support medical diagnosis and treatment within the same institution or health system. EMR use generally alludes to the transition of information to a digital form, that is, a form that can be used by electronic devices, such as computers. Various authors agree that EMRs can make an important contribution to increasing the quality of care $[1,2]$. However, how are EMR use and the quality of medical care related in a hospital context?

In previous studies, the two authors ( $\mathrm{RvP}$ and $\mathrm{KR}$ ) of this paper attempted to establish links between the extent of EMR use and the quality of medical care [3-5]. In those previous quantitative studies, they used a specially developed tool to measure the degree of EMR use in Dutch hospitals. This 8-stage (0-7) measurement tool, the so-called EMR Adoption Model (EMRAM) from the Healthcare Information and Management Systems Society (HIMSS) measures the adoption and use of EMR functions. EMRAM incorporates algorithms to score hospitals relative to their EMR capabilities and aims to encourage hospitals to use EMRs at a higher stage [6]. The HIMSS is a US not-for-profit organization dedicated to improving health care in its quality, safety, cost-effectiveness, and access through the best use of IT and management systems. It was founded in 1961 as the Hospital Management Systems Society. It is now headquartered in Chicago, IL, USA. The society has more than 80,000 individuals, 480 provider organizations, 470 nonprofit partners, and 650 health services organizations (as of December 2019). The HIMSS definition of an environment with a complete EMR (stage 7) is "an environment that is composed of the clinical data repository, clinical decision support, controlled medical vocabulary, order entry, computerized practitioner order entry, and clinical and physician documentation applications" [7]. Ultimately, the model should lead to the use of EMR systems so that the hospital no longer uses paper charts. The findings of the quantitative analysis in the previous studies [3-5] show that Dutch hospitals in 2014 particularly struggled with electronic nursing documentation. In 2012-2014, 37.5\% of Dutch hospitals were unable to upload this information to the EMRs. Once this challenge is met, the next challenge for Dutch hospitals will be to equip the EMRs with closed loop medication administration (CLMA) and an advanced clinical decision support system (CDSS). The CLMA is a fully electronic medication management process in which all relevant information is seamlessly documented. All the steps in the medication cycle (ordering, verifying, preparing, and administering) are supported electronically with decision support, where relevant. A CDSS is an application that analyzes data to help health care providers make decisions and improve patient care. A CDSS focuses on using knowledge management to obtain clinical advice based on multiple factors of patient-related data. It enables integrated workflows, provides assistance at the time of care, and offers care plan recommendations.
A 2015 study [4] tried to find a correlation between the EMRAM score and Elsevier performance indicators. This yearly Elsevier publication is a Dutch nationwide publication of quality indicators for hospitals. No statistically significant correlations were found.

In the 2017 study [5], a positive association between the use of EMRs and patient quality outcomes was found for the length of stay (LOS, the duration of a single episode of hospitalization) for patients with colorectal cancer in Dutch hospitals, as measured by the Dutch Surgical Colorectal Audit (DSCA).

In a third study (2018, not yet published, available from the first author [RvP]), we did not find a significant relationship between the EMRAM score and the number of patients with adverse events (AEs), preventable AEs, AEs caused by medication, number of re-admissions (RAs), and the LOS, as measured in the NIVEL study [8]. Our research team did not understand why a better EMRAM score does not lead to a better quality of care. We believed that two intervening aspects play a role: the implementation process itself and the role of medical specialists. We believed so because of several publications on both aspects.

The first of these is a paper written by Adler-Milstein et al [9], which emphasizes the importance of the implementation process of more mature IT systems for reaching higher quality. Recent studies suggest that unsuccessful implementation of EMR systems could be due to poorly designed EMR systems, poor use of EMRs by clinicians, or social organizational aspects, such as goal conflicts, lack of time, or lack of support from colleagues [10]. The second factor is the role of the medical specialist [11,12]. Previous studies show this is an important factor in the adoption and use [6] of EMR systems in hospitals. Medical specialists are a main frontline group of users of EMR systems. In addition, whether they support and effectively use EMR systems greatly influences other user groups in the medical institution, such as nurses, pharmacists, and administrative staff. To optimize EMR use, it is therefore essential to understand what physicians perceive to be key aspects that either support or hinder the use of EMR systems, which can positively impact medical treatment and care. To substantiate our ideas about not finding a relationship between the EMRAM score and the quality of care, we undertook this study with the following open research question:

\section{Which positive or negative aspects influence the relationship between EMR use and the quality of medical care according to medical specialists?}

In this paper, the term "EMR" can concern the data themselves, the accompanying procedures, or a fundamental change in method (so-called digital transformation).

\section{Methods}

\section{Design and Methodology}

To answer the research question, a qualitative research study was performed. A qualitative design was considered appropriate for this question, as the primary objective was to explore more in-depth perceptions of factors and processes related to a more complex system, including social and technical components [13]. 
The development of EMR use in 73 Dutch hospitals in the period of 2012-2015 was measured using the EMRAM score [14]. The hospitals that were measured twice in the research period and did not work with nursing documentation in EMRs or with the
CLMA and advanced CDSS were asked to participate in a follow-up study (Table 1). Two hospitals achieved a higher stage on the EMRAM score, eight hospitals stayed on the same level, and one did not respond (Table 1).

Table 1. Summary of participating hospitals based on the EMRAM ${ }^{\mathrm{a}}$ score.

\begin{tabular}{|c|c|c|c|}
\hline Participant number & Type of hospital & $\begin{array}{l}\text { Nursing documentation and CLMA }{ }^{\mathrm{b}} / \text { advanced } \\
\text { CDSS }^{\mathrm{c}} \text { in EMRs } \\
\text { d in } 2012-2014\end{array}$ & $\begin{array}{l}\text { Nursing documentation and CLMA/advanced } \\
\text { CDSS in EMRs in } 2018\end{array}$ \\
\hline 1 & $\mathrm{UMC}^{\mathrm{e}}$ & No & No \\
\hline 2 & UMC & No & Yes \\
\hline 3 & Teaching hospital & No & No \\
\hline 4 & Teaching hospital & No & No \\
\hline 5 & Teaching hospital & No & $N / A^{f}$ \\
\hline 6 & Teaching hospital & No & No \\
\hline 7 & Local hospital & No & No \\
\hline 8 & Local hospital & No & No \\
\hline 9 & Local hospital & No & No \\
\hline 10 & Local hospital & No & No \\
\hline 11 & Local hospital & No & Yes \\
\hline
\end{tabular}

a EMRAM: Electronic Medical Record Adoption Model.

${ }^{\mathrm{b}}$ CLMA: closed loop medication administration.

${ }^{\mathrm{c}} \mathrm{CDSS}$ : clinical decision support system.

${ }^{\mathrm{d}}$ EMR: electronic medical record.

${ }^{\mathrm{e}} \mathrm{UMC}$ : University Medical Centre.

${ }^{\mathrm{f}} \mathrm{N} / \mathrm{A}$ : not available.

The hospitals were approached through the chairs of their medical staff and were asked to nominate a medical specialist each to participate in this study. To be eligible, the medical specialists were required to have worked for more than 5 years in the hospital in question. Overall, the selection of participants was geared toward a balanced mix of different specialties (surgical, nonsurgical, small specialty).

In the period of August-October 2018, a semistructured interview of about 90 min was conducted with each medical specialist selected. The abovementioned research question was at the core of the interview. An item list (available from the first author $[\mathrm{RvP}]$ ) was used by the interviewer to help the participants focus on relevant experiences in case the conversation halted. We only asked questions about aspects the medical specialists were personally dealing with; we were not interested in second-hand accounts.
For analysis of the answers, we used the classification of aspects that can influence the implementation of EMR systems based on the taxonomy of Boonstra et al [15]. This systematic literature review was carried out to identify all the barriers that result in physicians showing resistance toward EMR systems. Table 2 shows the highlights of this taxonomy model.

We used this taxonomy for the same aspects in a neutral connotation, as the same taxonomy can be followed when categorizing aspects (quotes) as facilitators of EMR use. All authors participated in the allocation of quotes from the interviews to a category of the described taxonomy, with initial allocation by the first author (RvP) and validation by the second and third authors (AJPS and AB). The results were recorded in a Microsoft Excel file, which is available upon request from the first author (RvP). Based on this classification and the primary interview recordings, the authors reached a consensus about the best way to allocate quotes to the categories of the taxonomy. All authors agreed with the final allocation of quotes. 
Table 2. Summary of categories.

\begin{tabular}{ll}
\hline Quote category & Description \\
\hline $\begin{array}{l}\text { Technical } \\
\text { Psychological }\end{array}$ & $\begin{array}{l}\text { The technical aspects of the systems, the technical capabilities of the physicians and the suppliers } \\
\text { Concerns regarding the use of EMRs }{ }^{\mathrm{a}} \text { that are based on the medical specialists' personal issues, knowl- } \\
\text { edge, and perceptions } \\
\text { Relationships with the patients and fellow care providers but also with suppliers, insurers, and politicians }\end{array}$ \\
Social & $\begin{array}{l}\text { Time required to select, implement, and learn how to use EMR systems and subsequently enter data into } \\
\text { the system }\end{array}$ \\
Time & $\begin{array}{l}\text { Financial issues, including those related to monetary issues in implementing EMR systems } \\
\text { Finance }\end{array}$ \\
Pegal & $\begin{array}{l}\text { Orivacy or security concerns regarding patients' medical information } \\
\text { Organization }\end{array}$ \\
Change process & The influence of the organizational culture, incentives, community-level participation, and leadership \\
\hline
\end{tabular}

${ }^{\mathrm{a} E M R: ~ e l e c t r o n i c ~ m e d i c a l ~ r e c o r d . ~}$

\section{Ethics Approval and Consent to Participate}

As this study did not involve research on human subjects, no medical ethical committee approval was required under Dutch law. Neither the Dutch Medical Research Involving Human Subjects Act (Wet Medisch-Wetenschappelijk Onderzoek met Mensen [WMO]) nor the university required ethics approval for the type of work conducted in this research. All participants orally and voluntarily agreed to participate in this study. They allowed us to use the data they provided, including quotes, under the condition of confidentiality. All participants agreed with the final report of their interviews. All participating hospitals, medical specialists, and used quotes in the manuscript were anonymized. No written permission was needed in this case.

\section{Results}

\section{Participating Hospitals and Medical Specialists}

In all, 11 hospitals (Table 3) agreed to participate in this qualitative study, while 3 hospitals ( 1 regional and 2 teaching hospitals) were unwilling or unable to participate. Each participating hospital nominated 1 medical specialist to be interviewed, representing 10 different specialties and between 5 and 27 years of experience in their current hospital. Six of them were (former) chairs of medical staff.

Table 3. Summary of participating hospitals and medical specialists.

\begin{tabular}{|c|c|c|c|c|c|c|}
\hline Type of hospital & $\begin{array}{l}\text { Number of } \\
\text { hospitals (n) }\end{array}$ & $\begin{array}{l}\text { Number of spe- } \\
\text { cialists (n) }\end{array}$ & Type of specialist (n) & Age (years) & Gender (n) & $\begin{array}{l}\text { Number of years of } \\
\text { experience in hospital }\end{array}$ \\
\hline $\mathrm{UMC}^{\mathrm{a}}$ & 2 & $732-1050$ & $\begin{array}{l}\text { Internist (1) } \\
\text { Anesthetist (2) }\end{array}$ & $43-57$ & $\begin{array}{l}\text { Female (1) } \\
\text { Male (1) }\end{array}$ & $10-13$ \\
\hline Teaching hospital & 4 & $240-377$ & $\begin{array}{l}\text { Rheumatologist (3) } \\
\text { Radiologist (4) } \\
\text { Internist (5) } \\
\text { Surgeon (6) }\end{array}$ & $49-62$ & $\begin{array}{l}\text { Male (2) } \\
\text { Female (2) }\end{array}$ & $11-23$ \\
\hline Local hospital & 5 & $70-187$ & $\begin{array}{l}\text { Pediatric neurologist (7) } \\
\text { Vascular surgeon (8) } \\
\text { Gynecologist (9) } \\
\text { Cardiologist (10) } \\
\text { Pharmacist (11) }\end{array}$ & $42-59$ & Male (5) & $5-27$ \\
\hline
\end{tabular}

${ }^{\mathrm{a}} \mathrm{UMC}$ : University Medical Centre.

In total, the participants made 160 observations regarding aspects that influence the relationship between the extent of EMR use and the quality of care: 122 observations were characterized as barriers and 38 as facilitators. First, we will discuss the technical aspects that are mentioned most often. Next, we will discuss the other aspects of EMRs that influence the quality of care. Not every aspect of the taxonomy was used, because some aspects were not mentioned during the interviews. The legal aspect, related to information safety, was not mentioned in any of the interviews. The organizational aspect (type and size of the hospital) could not be addressed in the analysis because it was not part of the design of the study and was out of scope for individual participants. As explained in the Methods section, the change process aspect is of particular interest from a systems perspective, and it will be treated last to reflect on possible future developments.

The participating hospitals included two academic hospitals, four teaching hospitals, and five local hospitals (see also Tables 
1 and 3). However, based on hospital type, no difference was found between participants' observations. The availability of nursing documentation and of the CLMA and advanced CDSS in the hospital concerned did not lead to differences (see also Tables 1 and 3 ) in the experiences of the medical specialists.

\section{Technical Aspects}

During the interviews, technical aspects were the category all medical specialists chose to talk about first. It therefore seems like medical specialists consider technical aspects the most important factor influencing EMR use in hospitals. To provide more insight, the related tables include a subdivision of technical aspects, followed by quotes from participants to illustrate what the more abstract terms of the model mean. A complete list of all quotes is available from the first author (RvP).

\section{Customizability}

Customizability is the ability of the technology system to adapt to specific needs of the user. Within the technical aspects category, customizability (Table 4) was mentioned most often, more often as a barrier than as a facilitator. The medical specialists compared EMR systems in the hospital with intelligent systems that can be used at home to buy a book or book a trip. It seems as though an administrative system has simply been converted to a medical system.

Table 4. Customizability: illustrative quotes from participants.

\begin{tabular}{l} 
Quote type \\
\hline Barrier
\end{tabular}

Facilitator $\quad$ - "Innumerable positive points; accessible everywhere, even at home. No more illegible notes." (Participant 10)

- "Back in the day, the paper records often got lost. Lab results are available more quickly now, and the medical specialist can quickly see the daily reports of the nurses," (Participant 7)

\section{Interconnectivity/Standardization}

EMR hardware and software can be used straight out of the box, but they have to be interconnected with other devices that complement the EMR system. The exchange of dossiers is often not possible due to lack of standardization, and files are often split up between different specialties because that is how the medical practice is organized in the hospital (Table 5). Getting an integral view of a patient's situation is therefore difficult but especially important with multimorbid patients (an evergrowing group). General data, such as blood pressure, smoking, and alcohol use, are often contradictory and recorded more than once. Sometimes, multiple systems have to be simultaneously used during treatment because files are not linked-a situation that medical specialists consider potentially dangerous.

Table 5. Interconnectivity: illustrative quotes from participants.

\begin{tabular}{|c|c|}
\hline Quote type & Quote \\
\hline Barrier & 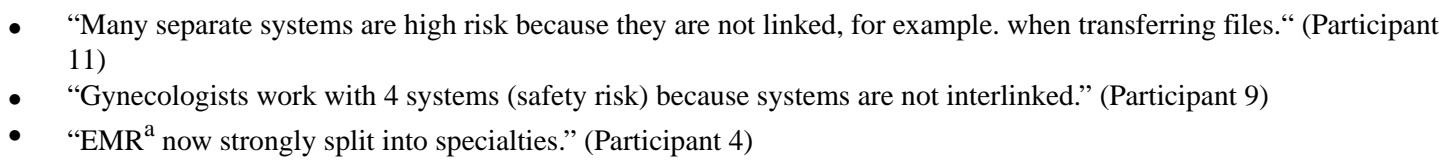 \\
\hline Facilitator & $\begin{array}{l}\text { - "Good-quality photos can be easily obtained." (Participant 7) } \\
\text { - "Back in the day, there was no background information available if the GP's }{ }^{b} \text { notification read 'diarrhea'; now there } \\
\text { is." (Participant 5) }\end{array}$ \\
\hline
\end{tabular}

${ }^{a}$ EMR: electronic medical records

${ }^{\mathrm{b}} \mathrm{GP}$ : general physician.

\section{Limitations of the System}

According to the participants, the IT system promises a great deal but offers little more than the old paper situation. Participants particularly point to the promised additional intelligence that is either absent from the system or present in a limited sense (Table 6). The system could offer, for example, so-called evidence-based advice based on the individual and combined patient data available in the system [16]. An oft-heard theme is also the lack of analytical tools to analyze the available data and to anticipate developments in the health of patients in the hospital. 
Table 6. Limitations of the IT system: illustrative quotes from participants.

\begin{tabular}{|c|c|}
\hline Quote type & Quote \\
\hline \multicolumn{2}{|c|}{ Obsolescence: the IT system reaching its limit, becoming obsolete, and no longer remaining useful } \\
\hline Barrier & 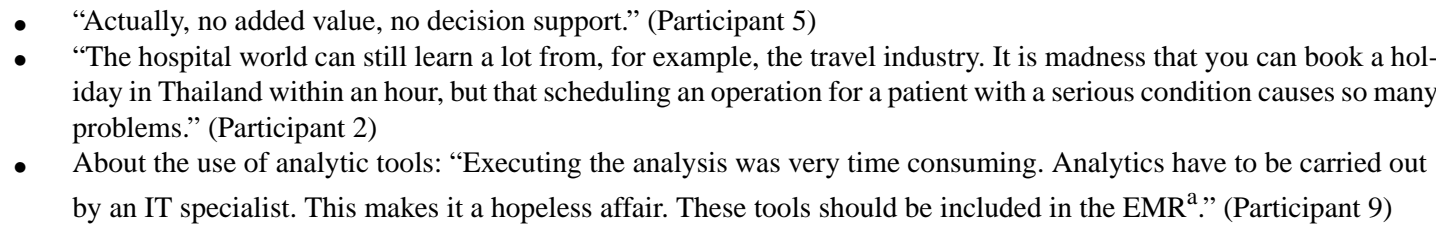 \\
\hline Facilitator & - "There is a little bit of decision support for medication (prescriptions)." (Participant 5) \\
\hline \multicolumn{2}{|c|}{ Complexity: EMRs resulting in physicians having to allocate time and effort if they are to master complexity } \\
\hline Barrier & - "Reporting of transactions [is] very complicated." (Participant 1) \\
\hline Facilitator & - $\quad \mathrm{N} / \mathrm{A}^{\mathrm{b}}$ \\
\hline \multicolumn{2}{|c|}{ Reliability: the dependability of the IT system } \\
\hline Barrier & - "In [the] case of failure of systems at polyclinic, nothing is available anymore." (Participant 7) \\
\hline Facilitator & - "Simple but works well. Very few malfunctions. Much better than paper." (Participant 9) \\
\hline
\end{tabular}

${ }^{a}$ EMR: electronic medical record.

${ }^{b}$ N/A: not available.

\section{Other Aspects of EMRs Influencing the Quality of Care}

In Table 7, other aspects of EMRs are summarized. These aspects were mentioned less often by the medical specialists but are also important influencing factors. These observations are generally consistent with the findings published elsewhere
$[17,18]$. One thing that stands out is that medical specialists sometimes miss informal contacts of meetings with colleagues that were previously necessary due to the lack of a common digital file. Equally striking is that the financial aspect was hardly mentioned. The latter contrasts with findings in other publications [16]. 
Table 7. Other aspects of EMRs ${ }^{\mathrm{a}}$ : illustrative quotes from participants.

\begin{tabular}{|c|c|}
\hline Quote type & Quote \\
\hline \multicolumn{2}{|c|}{ Computer skills of the physician or staff: technical knowledge and skills to deal with EMRs } \\
\hline Barrier & $\begin{array}{l}\text { - "Doctors are not IT savvy, [for] example, [a] radiologist who wants to look at photos at home but uses a home } \\
\text { PC }^{\text {b }} \text { that has not been updated and therefore does not work properly." (Participant } 8 \text { ) }\end{array}$ \\
\hline Facilitator & - $\quad N / A^{c}$ \\
\hline \multicolumn{2}{|c|}{ Training and support: associated with the EMR system } \\
\hline Barrier & $\begin{array}{l}\text { - "The system may not be used properly by medical specialist[s]: } \\
\text { - Too little knowledge of the system } \\
\text { - Possibilities not known } \\
\text { - Defensive medicine: hedge behavior." (Participant 4) }\end{array}$ \\
\hline Facilitator & - N/A \\
\hline \multicolumn{2}{|c|}{ Psychological: personal issues, knowledge, and perceptions } \\
\hline Barrier & $\begin{array}{l}\text { - "Check lists: system steers behavior. Against check lists: action is carried out anyway because I have prescribed } \\
\text { it. Medication verification is standard procedure, so why check?" (Participant 5) } \\
\text { - "There is a contrast between old and young specialists. I think the older ones accept a limited system more easily; } \\
\text { their demands are less high." (Participant 7) }\end{array}$ \\
\hline Facilitator & - "Enforces a certain treatment, and that is positive." (Participant 10) \\
\hline \multicolumn{2}{|c|}{ Social: relationships with patients and fellow care providers but also with suppliers, insurers, and politicians } \\
\hline Barrier & $\begin{array}{l}\text { - "Medical specialists clearly have ideas about each other. A lot of contradictions. Hard to get on the same page." } \\
\text { - "Barticipant 2) } \\
\text { there was only one photo; this meant people knew each other, radiology was the center, people walked in, it used } \\
\text { to run more smoothly. Now there is multidisciplinary consultation, but people don't know each other anymore." } \\
\text { (Participant 4) }\end{array}$ \\
\hline Facilitator & - "Member of medical staff (gynecologist) mans a so-called 'wailing wall'.” (Participant 8) \\
\hline
\end{tabular}

${ }^{\mathrm{a}} \mathrm{EMR}$ : electronic medical record.

${ }^{\mathrm{b}} \mathrm{PC}$ : personal computer.

${ }^{\mathrm{c}} \mathrm{N} / \mathrm{A}$ : not available.

\section{The Change Process Aspect}

In Table 8, illustrative quotes for the change process aspect are summarized. According to the medical specialists, several preconditions for success must be met before the successful introduction of EMRs in their hospitals. There is some doubt, for example, as to whether the supplier of EMRs is willing to create links to other parts of the IT system. However, this runs counter to market forces. Moreover, the participants mentioned that governmental institutions often also still require medical specialists to use paper. A central theme for almost all interviewed medical specialists is the coded or noncoded recording of obtained information. They generally realize that encoding a medical record is a prerequisite for getting help from the EMR system based on so-called evidence-based material. Several hospitals initially started out with the recording of this information by medical specialists but later abolished this system because the medical specialists refused to work with it. 
Table 8. The change process: illustrative quotes from participants.

\begin{tabular}{ll}
\hline The change process & Quote \\
\hline Support from organizational culture & $-\quad \begin{array}{l}\text { "There is too little attention for resistance in medical specialists due to, for example, time pressure." } \\
\text { (Participant 8) }\end{array}$ \\
- "Before, medical specialists were individual, had their own working methods. By now, a technological \\
revolution has taken place (paper records are now electronic records). But people do not want to change \\
$(95 \%)$. They have to get out of their comfort zone. You have to invest in that. Now, medical specialists' \\
approach EMR ${ }^{\mathrm{a}}$ as if it were paper." (Participant 10) \\
- "The problem is that hospitals are not IT minded. Hospitals are not flexible." (Participant 10)
\end{tabular}

Leadership — "On its own, the market will not provide properly functioning IT systems for hospitals." (Participant 2)

- "Cytostatic control by pharmacies should be done via inspection on paper." (Participant 8)

- "Participant sees movement from specialism based (departments) towards disease related. For example, a department of bowel cancer with [an] internist, [an] $\mathrm{MDL}^{\mathrm{b}}$, [an] oncologist, and [a] radiologist. This has an impact on the way digitization is organized." (Participant 4)

- " $\quad$ (EMR supplier mentioned) is monopolist. Does not listen to customer." (Participant 4)

Incentives

Participation
- "On its own, the market will not provide properly functioning IT systems for hospitals, for example, the market does not benefit from the exchangeability of data. Market forces therefore do not lead to the solution." (Participant 2)

- "No 'reward' for 'good' use." (Participant 8)

- "Conclusion: Letting medical specialists do coding work is undesirable, but it is necessary to enable systems to 'offer help' on a more advanced level. This process should be structured differently by giving supporting staff a role in it." (Participant 8)

${ }^{\mathrm{a}}$ EMR: electronic medical record.

${ }^{\mathrm{b}} \mathrm{MDL}$ : maag-darm-lever in Dutch, meaning gastroenterologist.

\section{Discussion}

\section{Preliminary Findings}

To answer the research question "Which positive or negative aspects influence the relationship between EMR use and the quality of medical care according to medical specialists?", a qualitative research study was performed.

The overall picture of the relationship between the extent of EMR use and the quality of medical care according to the participants shows that medical specialists prefer digital records over old paper ones. However, at the same time, the participants consider the technical systems old-fashioned compared to the systems they can access at home to book a trip or buy a book. The inability of all those involved (professional groups, boards, suppliers, politicians) to improve this situation is described openly by some participants. By and large, the participants do see the potential, but a better way to record coded information still needs to be found. The lack of interconnection between the different EMRs, for example, per hospital department (eg, internal medicine and cardiology), is also seen as an important limitation. Noteworthy is also that financial aspects are not mentioned often. This contrasts with other studies, in which technical issues and financial issues are mentioned in equal measure [12]. The obvious question is then whether money plays an important role according to medical specialists. Finally, these systems should be able to offer support in decision making for diagnosis and treatment [19].

The participants indicated that it is necessary to fulfil some of the preconditions for success before the EMR can make a positive contribution to the hospital's daily practice. That is essentially the source of the medical specialist's resistance. It takes a lot of effort and time to keep the patient file up to date. The only result is a nonpaper file, which medical specialists appreciate but is ultimately not enough to motivate them. It is tempting to make encoding medical data mandatory. However, without interventions in the organization, this is doomed to fail because many medical specialists are unwilling or unable to comply. In the end, inefficiently organized processes will then be automated at great cost and effort, while remaining inefficient at their core [20].

So, prior to the question of how to improve the available processes comes the basic question, What can be improved? Are the available business processes principally accepted, or can the search be directed toward a change in the existing processes [21]?

As stated, it is essential to understand what medical specialists perceive to be key aspects that either support or hinder the use of EMRs to positively impact diagnosis and treatment, now and in the future. These findings may help decide how medical processes can be improved with modern IT. Important in this approach is that the possibilities of modern IT, especially for advanced decision support, be taken as a starting point [22].

\section{Limitations of the Study}

Our study had several limitations. We only interviewed medical specialists from hospitals that lacked nursing documentation in 2012-2014. These hospitals found themselves at the lowest stage of EMR use according to the EMRAM model but also had great potential to improve effectively and were able to learn from other hospitals. However, this qualitative study might still have 
been too early in the hospitals' implementation of EMRs to identify aspects that are relevant for mature use of EMRs.

The age of the interviewed medical specialists varied between 42 and 62 years. These are medical specialists with a great deal of experience in the field. A question is whether the perspectives of younger medical specialists correspond with the perspectives of their older colleagues. Follow-up research might answer this question.

\section{Conclusions}

The 11 medical specialists shared positive experiences of EMR use when comparing it to the formerly used paper records. The fact that the health professionals involved can access patient data at any time they need it is considered important. However, in practice, potential quality improvement lags as long as decision support cannot be applied due to the lack of a fully coded patient record.

\section{Acknowledgments}

The authors wish to thank Leonard Witkamp, professor of telemedicine at UMC Amsterdam, for his valuable early review of the article.

\section{Authors' Contributions}

RvP planned and conceptualized the study, developed the interview guide, acquired data, analyzed and interpreted data, and drafted the manuscript. GS assisted in developing the interview guide and was involved in interpretating the data, preparing an early version of the manuscript, and revising the manuscript. AB assessed the adapted use of the taxonomy, as published in [15]. KR supervised the study. All authors have read and approved the final manuscript. The data sets generated or analyzed during this study are available, after anonymization, from the corresponding author upon reasonable request.

\section{Conflicts of Interest}

The authors declare that they have no competing interests. No funding was acquired.

\section{References}

1. Lin Y, Lin M, Chen H. Do electronic health records affect quality of care? Evidence from the HITECH Act. Inf Syst Res 2019 Mar;30(1):306-318 [FREE Full text] [doi: 10.1287/isre.2018.0813]

2. Wani D, Malhotra M. Does the meaningful use of electronic health records improve patient outcomes? J Oper Manag 2018 Jun 22;60(1):1-18. [doi: 10.1016/j.jom.2018.06.003]

3. van Poelgeest R, Daniels J, de Leeuw RJ, Schrijvers G. Profile of the Digitization of Patient Medical Records in Dutch Hospitals.: HIMSS; 2015 Oct 15. URL: http://www.jhimdigital.org/jhim/fall 2015?pg=38\#pg38 [accessed 2021-10-18]

4. van Poelgeest R, Heida J, Pettit L, de Leeuw RJ, Schrijvers G. The association between eHealth capabilities and the quality and safety of health care in the Netherlands: Comparison of HIMSS Analytics EMRAM data with Elsevier's 'The Best Hospitals' data. J Med Syst 2015 Sep 5;39(9):90-96 [FREE Full text] [doi: 10.1007/s10916-015-0274-7] [Medline: 26242750]

5. van Poelgeest R, Groningen GJ, Daniels J, Roes K, Wiggers T. Level of Digitization in Dutch Hospitals and the Lengths of Stay of Patients with Colorectal Cancer.: Springer; 2017 Apr 08. URL: https://link-springer-com.proxy.library.uu.nl/ article/10.1007/s10916-017-0734-3 [accessed 2021-10-18]

6. Healthcare Information and Management Systems Society. Electronic Medical Record Adoption Model (EMRAM). 2013. URL: https://www.himss.org/what-we-do-solutions/digital-health-transformation/maturity-models/ electronic-medical-record-adoption-model-emram [accessed 2021-10-19]

7. Li R, Niu Y, Scott SR, Zhou C, Lan L, Liang Z, et al. Using electronic medical record data for research in a Healthcare Information and Management Systems Society (HIMSS) Analytics Electronic Medical Record Adoption Model (EMRAM) stage 7 hospital in Beijing: cross-sectional study. J Med Internet Res 2021 Aug 03;9(8):e24405 [FREE Full text] [doi: 10.2196/24405] [Medline: 34342589 ]

8. Baines R, Langelaan M, de Bruijne M, Spreeuwenberg P, Wagner C. How effective are patient safety initiatives? A retrospective patient record review study of changes to patient safety over time. BMJ Qual Saf 2015 Sep;24(9):561-571 [FREE Full text] [doi: 10.1136/bmjqs-2014-003702] [Medline: 26150548]

9. Adler-Milstein J, Woody Scott K, Jha A. Leveraging EHRs to improve hospital performance: the role of management. Am J Manag Care 2014 Nov;20(11 Spec No. 17):SP511-SP519 [FREE Full text] [Medline: 25811825]

10. Yen P, McAlearney AS, Sieck C, Hefner J, Huerta T. Health information technology (HIT) adaptation: refocusing on the journey to successful HIT implementation. J Med Internet Res 2017 Sep 07;5(3):e28 [FREE Full text] [doi: 10.2196/medinform.7476] [Medline: 28882812]

11. Lakbala P, Dindarloo K. Physicians' perception and attitude toward electronic medical record. Springerplus 2014;3:63 [FREE Full text] [doi: 10.1186/2193-1801-3-63] [Medline: 24516790]

12. Ankem K, Turpin J, Uppala V. Physician adoption of electronic health records: a visualisation of the role of provider and state characteristics in incentive programme participation. 2016. URL: http://informationr.net/ir/21-2/paper715.html\#. YW5OkRpByUk [accessed 2021-10-19]

13. Yin RK. Qualitative Research from Start to Finish. New York; London: GUILFORD PRESS; 2011. 
14. Pettit L. Understanding EMRAM and how it can be used by policy-makers, hospital CIOs and their IT teams. World Hosp Health Serv 2013;49(3):7-9. [Medline: 24377140]

15. Boonstra A, Broekhuis M. Barriers to the acceptance of electronic medical records by physicians from systematic review to taxonomy and interventions. BMC Health Serv Res 2010 Aug 06;10:231 [FREE Full text] [doi: 10.1186/1472-6963-10-231] [Medline: 20691097]

16. Frankovich J, Longhurst CA, Sutherland SM. Evidence-based medicine in the EMR era. N Engl J Med 2011 Nov 10;365(19):1758-1759. [doi: 10.1056/nejmp1108726]

17. Gagnon M, Simonyan D, Ghandour EK, Godin G, Labrecque M, Ouimet M, et al. Factors influencing electronic health record adoption by physicians: a multilevel analysis. Int J Inf Manag 2016 Jun;36(3):258-270. [doi: 10.1016/j.ijinfomgt.2015.12.002]

18. Granja C, Janssen W, Johansen MA. Factors determining the success and failure of eHealth interventions: systematic review of the literature. J Med Internet Res 2018 May 01;20(5):e10235 [FREE Full text] [doi: 10.2196/10235] [Medline: 29716883]

19. Sutton R, Pincock D, Baumgart D, Sadowski D, Fedorak R, Kroeker K. An overview of clinical decision support systems: benefits, risks, and strategies for success. NPJ Digit Med 2020;3:17. [doi: 10.1038/s41746-020-0221-y] [Medline: 32047862]

20. Porter M, Lee T. The Strategy That Will Fix Health Care. 2013. URL: https://hbr.org/2013/10/ the-strategy-that-will-fix-health-care [accessed 2021-10-19]

21. Badiru AB. Systems Engineering Models: Theory, Methods,Applications. NY: CRC Press; 2019.

22. Jenders RA. Advances in clinical decision support: highlights of practice and the literature 2015-2016. Yearb Med Inform 2017 Aug 19;26(01):125-132. [doi: 10.1055/s-0037-1606493]

\author{
Abbreviations \\ AE: adverse event \\ CDSS: clinical decision support system \\ CLMA: closed loop medication administration \\ DSCA: Dutch Surgical Colorectal Audit \\ EMR: electronic medical record \\ EMRAM: Electronic Medical Record Adoption Model \\ HIMSS: Healthcare Information and Management Systems Society \\ GP: general physician \\ MDL: maag-darm-lever \\ NIVEL: Netherlands Institute for Health Services Research \\ LOS: length of stay \\ PC: personal computer \\ UMC: University Medical Centre \\ WMO: Wet Medisch-Wetenschappelijk Onderzoek met Mensen
}

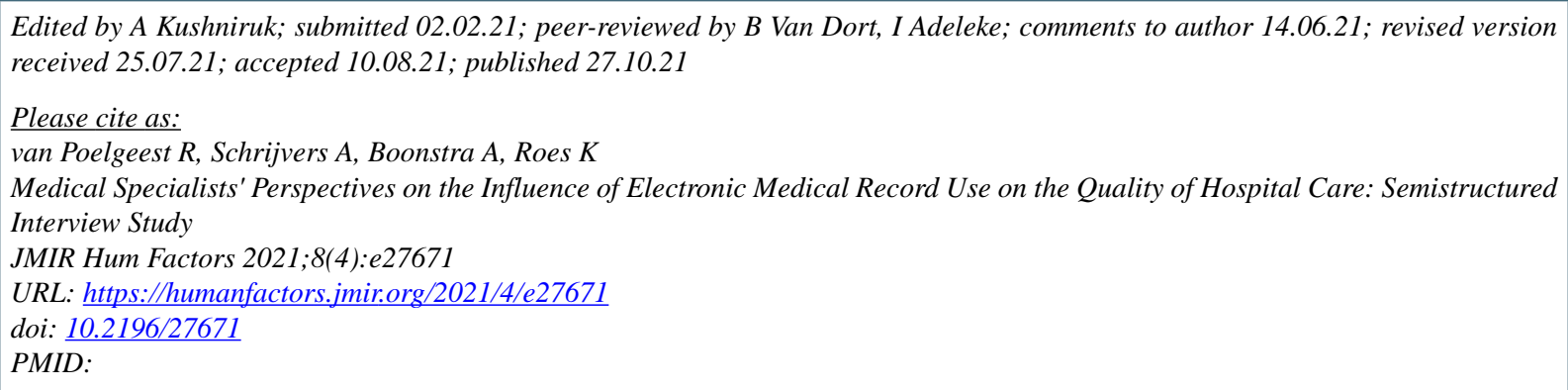

CRube van Poelgeest, Augustinus Schrijvers, Albert Boonstra, Kit Roes. Originally published in JMIR Human Factors (https://humanfactors.jmir.org), 27.10.2021. This is an open-access article distributed under the terms of the Creative Commons Attribution License (https://creativecommons.org/licenses/by/4.0/), which permits unrestricted use, distribution, and reproduction in any medium, provided the original work, first published in JMIR Human Factors, is properly cited. The complete bibliographic information, a link to the original publication on https://humanfactors.jmir.org, as well as this copyright and license information must be included. 